\title{
Assessing the Effects of Acute Amyloid $\beta$ Oligomer Exposure in the Rat
}

\author{
Ryan S. Wong, David F. Cechetto and Shawn N. Whitehead * \\ Vulnerable Brain Laboratory, Department of Anatomy and Cell Biology, Schulich School of Medicine and \\ Dentistry, University of Western Ontario, 1151 Richmond St, London, ON N6A 5C1, Canada; \\ ryanswong@gmail.com (R.S.W.); cechetto@uwo.ca (D.F.C.) \\ * Correspondence: shawn.whitehead@schulich.uwo.ca; Tel.: +1-519-661-2111 (ext. 80440)
}

Academic Editors: Amal Kaddoumi and Loqman Mohamed

Received: 17 July 2016; Accepted: 18 August 2016; Published: 24 August 2016

\begin{abstract}
Alzheimer's disease (AD) is the most common form of dementia, yet there are no therapeutic treatments that can either cure or delay its onset. Currently, the pathogenesis of AD is still uncertain, especially with respect to how the disease develops from a normal healthy brain. Amyloid $\beta$ oligomers $(\mathrm{A} \beta \mathrm{O})$ are highly neurotoxic proteins and are considered potential initiators to the pathogenesis of $\mathrm{AD}$. Rat brains were exposed to $\mathrm{A} \beta \mathrm{O}$ via bilateral intracerebroventricular injections. Rats were then euthanized at either 1,3,7 or 21-days post surgery. Rat behavioural testing was performed using the Morris water maze and open field tests. Post-mortem brain tissue was immunolabelled for $A \beta$, microglia, and cholinergic neurons. Rats exposed to $A \beta O$ showed deficits in spatial learning and anxiety-like behaviour. Acute positive staining for $A \beta$ was only observed in the corpus callosum surrounding the lateral ventricles. A $\beta O$ exposed rat brains also showed a delayed increase in activated microglia within the corpus callosum and a decreased number of cholinergic neurons within the basal forebrain. Acute exposure to $\mathrm{A} \beta \mathrm{O}$ resulted in mild learning and memory impairments with co-concomitant white matter pathology within the corpus callosum and cholinergic cell loss within the basal forebrain. Results suggest that acute exposure to $\mathrm{A} \beta \mathrm{O}$ in the rat may be a useful tool in assessing the early phases for the pathogenesis of AD.
\end{abstract}

Keywords: Alzheimer's disease; amyloid $\beta$ oligomers; behavioural deficits; microglial activation; cholinergic neuron depletion

\section{Introduction}

Alzheimer's disease (AD) is one of the most common forms of dementia. Since the discovery of $\mathrm{AD}$, our understanding of disease initiation and progression have revolved around amyloid $\beta(\mathrm{A} \beta)$ peptides [1-4]. A $\beta$ peptides are derived from sequential cleavage of the amyloid precursor protein (APP) and can exist in a several forms, such as monomers, oligomers, protofibrils and fibrils [5-11]. Although much is known about the disease, the earliest triggers and pathogenesis of AD is still not fully understood.

The amyloid cascade hypothesis is still one of the leading theories on AD initiation and progression. [12]. This hypothesis posits that $\mathrm{A} \beta$ peptides and insoluble plaques initiate a cascade of pathological events leading to the aberrant phosphorylation of tau, neuronal loss and eventual dementia $[13,14]$. Indeed, $\mathrm{A} \beta$ plaques and neurofibrillary tau tangles are still considered the gold standard in terms of post-mortem disease confirmation [15]. Although evidence in the literature has supported the amyloid cascade hypothesis, it does not fully explain the progression of the disease.

More recent evidence has shown that amyloid plaques may not be the primary initiator of the pathogenesis of $\mathrm{AD}$, largely based on the poor correlation between amyloid plaques and the severity cognitive impairment [16-19]. Furthermore, a study using post-mortem human brain analysis revealed 
the presence of amyloid plaques in six of the nine non-demented elderly patients [20]. In an animal study, transgenic mice containing the mutation for the human APP gene (Tg2576), did not show cognitive deficits until five months after extracellular deposition of amyloid plaques [21]. Together, these evidence suggests that amyloid plaques, although play a role in the pathogenesis of most $\mathrm{AD}$ cases, may not be entirely responsible and furthermore may not play a critical role in the pathogenesis of the prodromal phase of Alzheimer's disease.

Increasing evidence supports the role of the oligomeric form of the $A \beta$ peptide $(A \beta O)$ as being the critical initiator of toxicity in the pathogenesis of $\mathrm{AD}$. $\mathrm{A} \beta \mathrm{O}$ has been shown to be more neurotoxic than the $\mathrm{A} \beta$ fibrils that form plaques. [22]. Unlike amyloid plaques, $\mathrm{A} \beta \mathrm{O}$ in humans have been shown to correlate well with the severity of the disease, such as synaptic changes and neurodegeneration $[18,23]$. In a clinical study, $\mathrm{A} \beta \mathrm{O}$ in human $\mathrm{AD}$ cortical brain extracts were approximately 12 -fold higher than their age-matched control groups [16]. In another study, human $\mathrm{AD}$ cortical brain extracted $\mathrm{A} \beta \mathrm{O}$ injected into rat brains impaired synaptic plasticity and learning behaviours as shown by the passive avoidance conditioning test [24]. These clinical data all suggest that $\mathrm{A} \beta \mathrm{O}$ play a critical role in the pathogenesis of $\mathrm{AD}$.

The neurotoxic effects of $A \beta O$ have been established in many in vitro studies. When incubating $\mathrm{A} \beta \mathrm{O}$ with hippocampal cells, $\mathrm{A} \beta \mathrm{O}$ have been shown to co-localize with post-synaptic dendrites in vitro and disrupt long term potentiation (LTP) [25-28]. Other studies have suggested that A $\beta O$ can activate microglial cells by binding to receptors and increase inflammatory responses [29-31]. In vivo studies have also supported the role of $\mathrm{A} \beta \mathrm{O}$ in the pathogenesis of $\mathrm{AD}$. Studies using transgenic $\mathrm{AD}$ animal models, such as the Tg2576 mice model, have detected $\mathrm{A} \beta \mathrm{O}$ in the brain prior to plaque deposition, and its presence correlated with cognitive deficits in spatial learning and memory, as observed with the Morris water maze task $[21,32,33]$. Other studies have shown that injecting A $\beta O$ into the rat brain can inhibit long term potentiation, which can then be abrogated by treating the rats with $\mathrm{A} \beta \mathrm{O}$-specific antibodies $[34,35]$. These studies have provided some insight into the effects of $\mathrm{A} \beta \mathrm{O}$ in a physiological environment. However, our understanding of $\mathrm{A} \beta \mathrm{O}$ in vivo is incomplete and requires further investigation.

To investigate the effects of $A \beta O$ in vivo, we injected synthetic $A \beta O$ in the lateral ventricles of the rat brain. Although synthetic $\mathrm{A} \beta \mathrm{O}$ may be less potent than the naturally-secreted from cells or human-derived $\mathrm{A} \beta \mathrm{O}$, studies have shown similar neurotoxic effects [36,37]. Furthermore, synthetic $\mathrm{A} \beta \mathrm{O}$ are accessible and can be reproduced in the lab following established, reproducible protocols. We assessed changes in spatial learning and memory using the Morris water maze task and exploratory and anxiety-like behaviours using the open field task. We assessed the pathological outcome by immunolabelling for A $\beta$, Ox- 6 and IBA- 1 for microglia and choline acetyl transferase (ChAT) for basal forebrain cholinergic neurons. To our knowledge this is the first in vivo study to perform a single injection $A \beta O$ into the lateral ventricles and assess pathological and behavioural outcomes. Our study demonstrates, for the first time, that $\mathrm{A} \beta \mathrm{O}$ resulted in a transient behavioural deficits, transient $\mathrm{A} \beta$ deposition and sustained microglia activation.

\section{Results}

\subsection{Transient Deficits in Spatial Memory and Mild Anxiety-Like Behaviour in A BO-Injected Rats}

The Morris water maze task was used to determine whether exposure to $\mathrm{A} \beta \mathrm{O}$ in rats would result in deficits in spatial learning and memory (Figure 1A-C). During the spatial learning phase, both the A $\beta O$-injected and control (PBS-injected) rats were able to successfully learn the location of the hidden platform, however the $\mathrm{A} \beta \mathrm{O}$-injected rats performed poorer, as indicated by a longer latency to reach the platform (control-17.35 $\pm 1.86 \mathrm{~s}, \mathrm{~A} \beta \mathrm{O}-29.06 \pm 5.40 \mathrm{~s}$ ) on day 9 compared to control rats (Figure 1A). Probe trials at post-surgery day 12 and 19 was performed to assess any effects on short- or long-term spatial memory respectively (Figure 1B). A $\beta \mathrm{O}$-injected rats took significantly longer to reach the platform on probe trial day 12 than the control rats (control $-6.81 \pm 0.85 \mathrm{~s}, \mathrm{~A} \beta \mathrm{O}-18.01 \pm 4.71 \mathrm{~s}$ ). 
No differences in latency to reach the platform were observed by probe trial day 19 . To insure that the differences in task performance wasn't caused by motor, or other physiological deficits unrelated to $\mathrm{A} \beta \mathrm{O}$ exposure, cued learning trials were performed on days 20 and 21 post-surgery (Figure $1 \mathrm{C}$ ). No differences in swim speed were detected between A $\beta O$ - and PBS-injected rats.

A

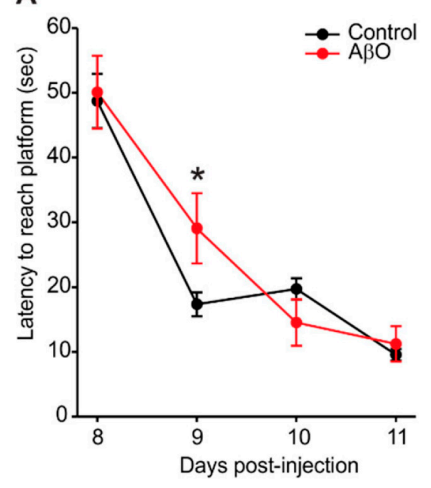

D

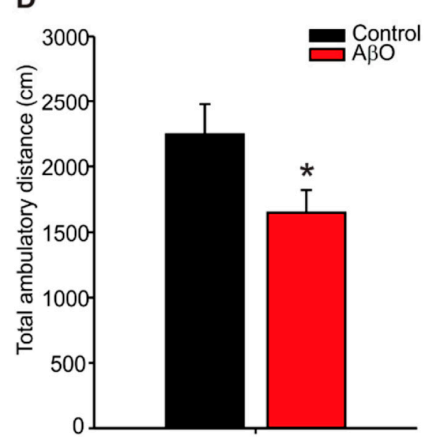

B

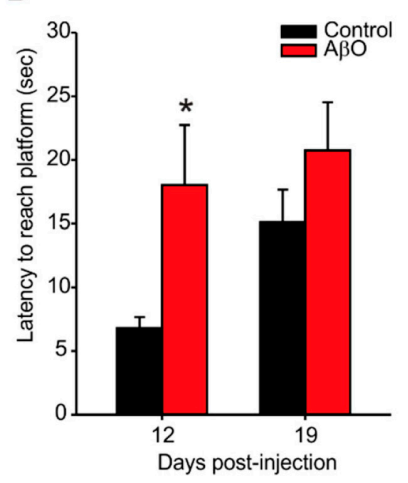

E

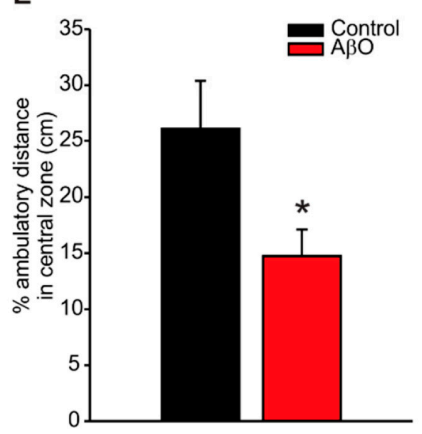

C

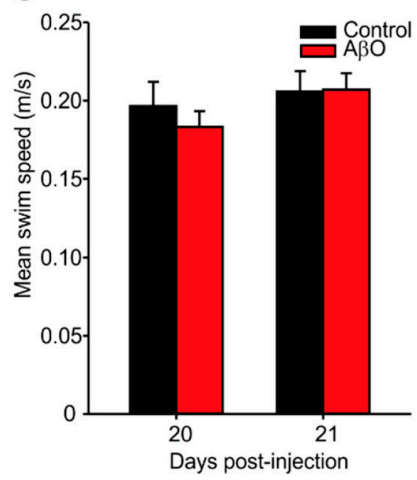

$\mathbf{F}$

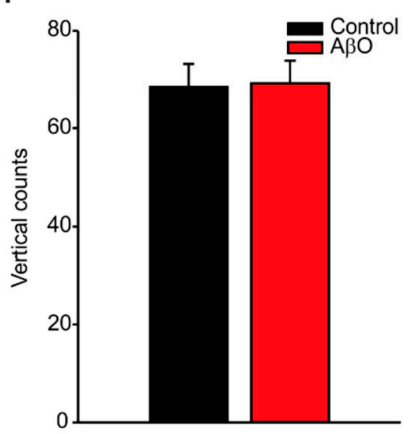

Figure 1. Behavioural assessment using the Morris water maze (A-C) and open field tasks (D-F). (A) Latency to reach platform was measured on post-surgical days 8-11 to assess initial learning of the task. A $\beta \mathrm{O}$-injected rats took significantly longer to reach the platform on day 9 compared to control rats; (B) probe trials were performed on days 12 and 19 to assess memory. A $\beta O$-injected rats took significantly longer to reach the platform on day 12 compared to controls; (C) mean swim time indicated no differences in swim speed between $\mathrm{A} \beta \mathrm{O}$-injected and control rats; (D) A $\beta \mathrm{O}$-injected rats showed significantly less ambulatory time compared to controls in the open field task; (E) A $\mathrm{OO}$-injected rats spent significantly less time in the central zone compared to control rats; $(\mathbf{F})$ no differences in motor ability detected using vertical counts between $\mathrm{A} \beta \mathrm{O}$-injected and control rats. Data presented as group means \pm SEM. * indicates statistical significance between $A \beta O$-injected and control rats using 2-way ANOVA followed by Tukey's post hoc analysis $(\mathbf{A}, \mathbf{B})$ and a 2-tailed students $t$-test $(\mathbf{D}, \mathbf{F}), p<0.05, n=8$ for each experimental group.

On post-surgery day 21, rats were placed in an open field apparatus for twenty minutes to test for exploratory and anxiety-like behaviours (Figure 1D-F). A $\beta O$-injected rats demonstrated significantly less ambulatory travel distance compared to controls (Figure 1D, control-2245.53 $\pm 230.49 \mathrm{~cm}$, $\mathrm{A} \beta \mathrm{O}-1649.44 \pm 172.99 \mathrm{~cm}$ ) and specifically, significantly less ambulatory distance traveled in the central zone compared to controls (Figure 1E, control-26.06\% $\pm 4.32 \%, \mathrm{~A} \beta \mathrm{O}-14.73 \% \pm 2.37 \%$ ), indicating an anxiety-like thigmotactic behaviour.

\subsection{Transient Deposition of $A \beta$ Following $A \beta O$ Injections}

We next investigated whether or not the $A \beta O$ injections would result in $A \beta$ deposition in the brain as well as to identify where the deposition may occur, and for how long it might in the brain. 
To identify $A \beta$ deposition, immunohistochemical stains were done with $A \beta 4 G 8$ antibody, which recognizes the 17-24 amino acid sequence of the $A \beta$ protein (Figure 2). There was only one region within the brain that demonstrated positive $\mathrm{A} \beta 4 \mathrm{G} 8$ labelling-the corpus callosum and cingulate gyrus adjacent to the injection sites, but remote from the injection sites themselves. In this region a transient increase in A $\beta 4 \mathrm{G} 8$ labelling was observed in A $\beta \mathrm{O}$-injected rats compared to controls. Quantification of A $\beta 4 G 8$ labelling revealed a significant increase in signal both at 1 and 3 days post-injection compared to controls (Figure 1B). By 7 days post-injection there were no differences in $\mathrm{A} \beta 4 \mathrm{G} 8$ labelling between $\mathrm{A} \beta \mathrm{O}$-injected rats and controls (Figure $1 \mathrm{~B}$ ) indicating that any $\mathrm{A} \beta$ deposition caused by the $\mathrm{A} \beta \mathrm{O}$-injection was likely cleared from the brain parenchyma.

A
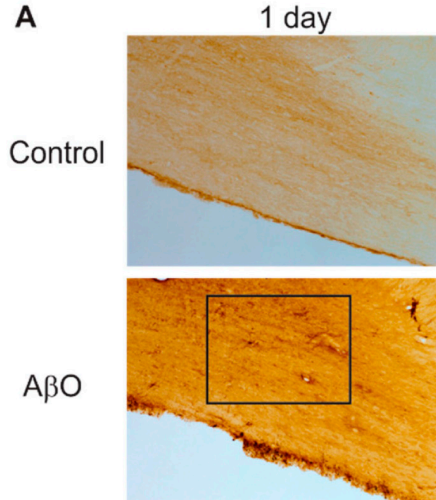

$\mathrm{A} \beta \mathrm{O}$

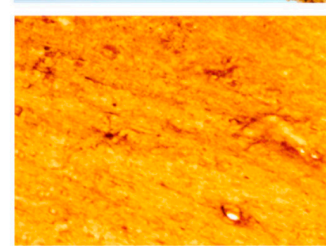

3 days
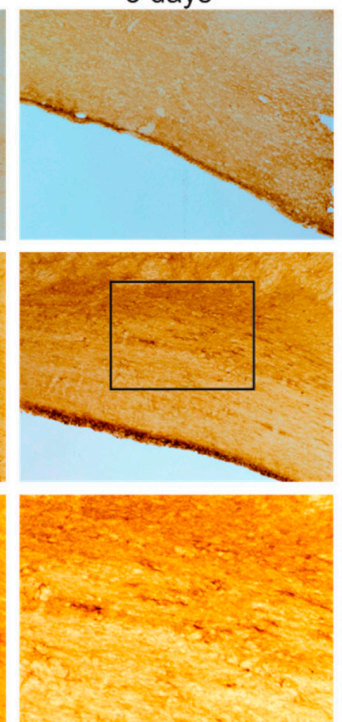

7 days
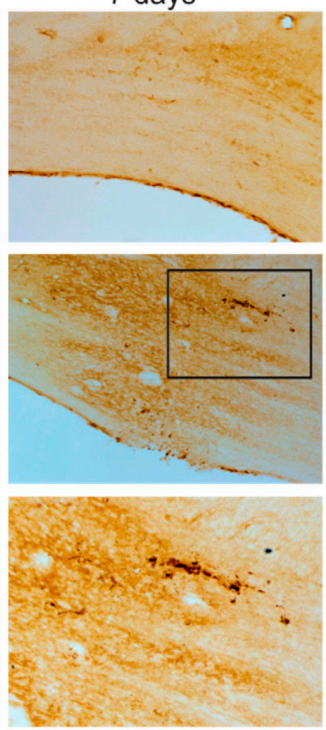

21 days

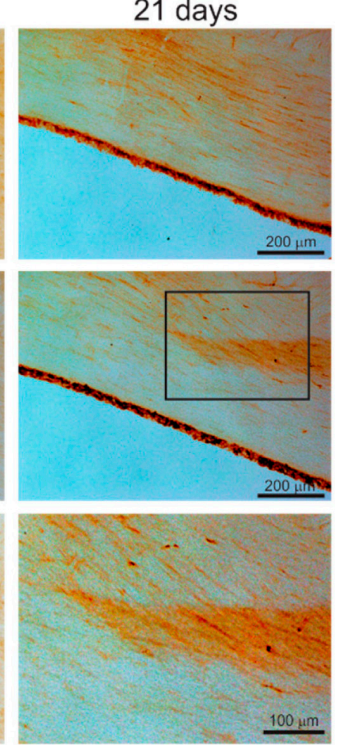

B

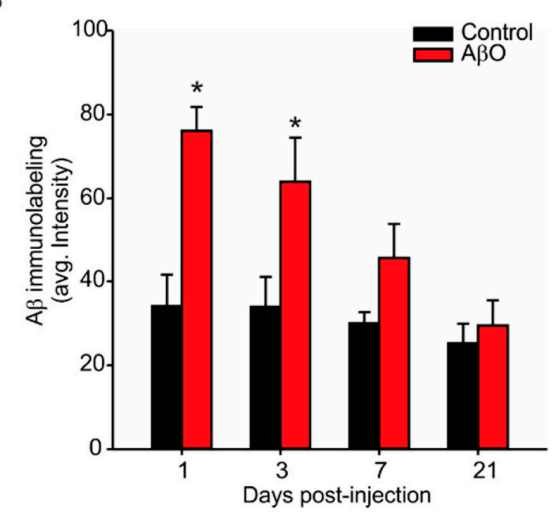

Figure 2. Immunolabelling for $A \beta$ deposition within the corpus callosum and cingulate gyrus. Paraformaldehyde perfused rat brains were sectioned at $30 \mu \mathrm{m}$ and stained with the A $\beta 4 \mathrm{G} 8$ antibody with an epitope against the 17-24 amino acid sequence of the $A \beta$ peptide. (A) Photomicrographs of the corpus callosum and cingulate gyrus in coronal rat brain sections from $\mathrm{A} \beta \mathrm{O}$-injected and PBS-injected (control) rats 1, 3, 7 and 21 days post-injection. Bottom panels are higher magnification images of the panels immediately above (indicated by the box). Scale bars are 200 or $100 \mu \mathrm{m}$ as indicated; (B) quantification using optical densitometry from three adjacent tissue sections per animal. $\mathrm{A} \beta \mathrm{O}$-injected rats had significantly more $\mathrm{A} \beta$ labelling in the corpus callosum and cingulate gyrus compared to controls at days 1 and 3 post-injection. Data presented as group means $\pm \mathrm{SEM}$. * indicates statistical significance between A $\beta O$-injected and control rats using 2-way ANOVA followed by Tukey's post hoc analysis, $p<0.05, n=5$ for each experimental group. 


\subsection{Cholinergic Neuron Depletion within Basal Forebrain Following A $\beta O$ Injections}

Pathological changes in AD patients include cholinergic neuron loss within the basal forebrain [38]. Specifically, cholinergic neuron loss occurs within the medial septal nucleus (MS) and vertical and horizontal diagonal bands of Broca of the basal forebrain. In this study cholinergic neurons were labelled with choline acetyltransferase (ChAT, Figure 3). By 21 days post-injection A $\beta O$-injected rats had significantly less ChAT positive neurons within the basal forebrain compared to controls (Figure 3B, control $-26.06 \pm 4.31$ cells, $\mathrm{A} \beta \mathrm{O}-14.73 \pm 2.38$ cells).

A

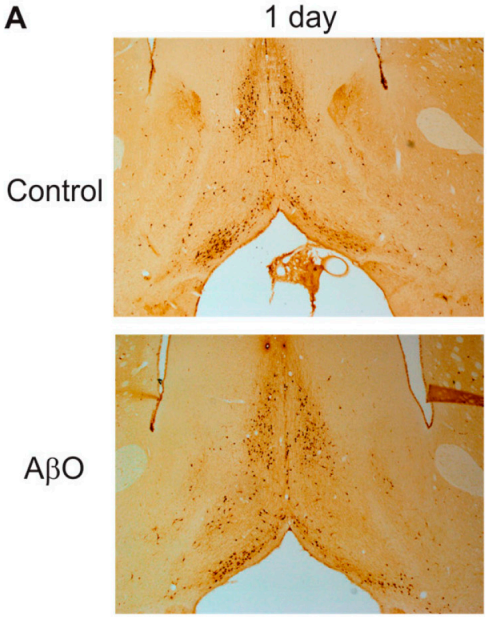

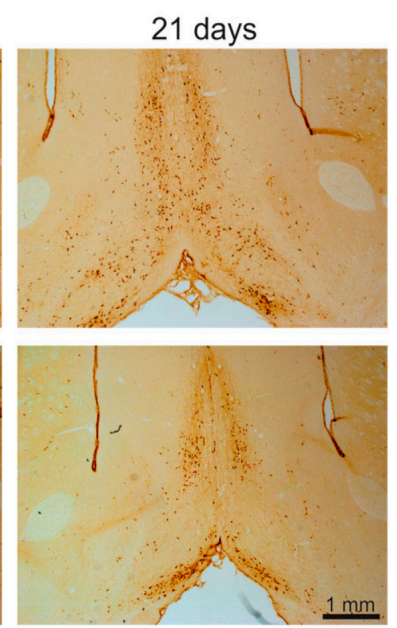

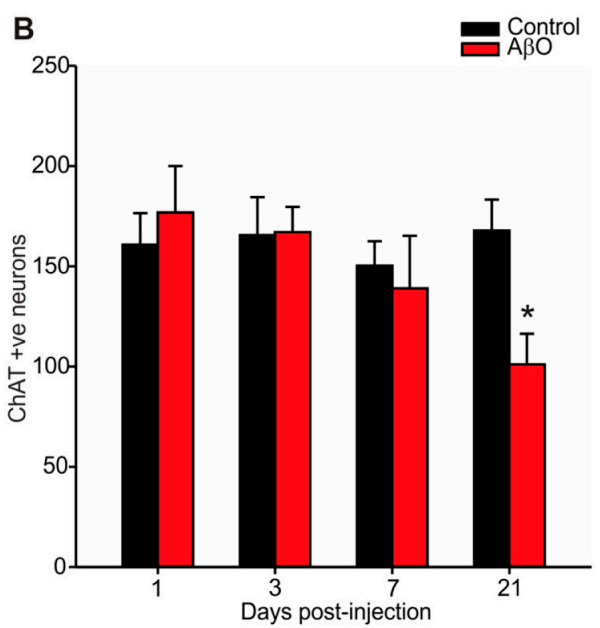

Figure 3. Immunolabelling for cholinergic neurons within the basal forebrain. Paraformaldehyde perfused rat brains were sectioned at $30 \mu \mathrm{m}$ and stained with the ChAT antibody that specifically labels cholinergic neurons within the basal forebrain. (A) Photomicrographs of the basal forebrain in coronal rat brain sections from $\mathrm{A} \beta \mathrm{O}$-injected and PBS-injected (control) rats 1, and 21 days post-injection. Scale bar is $1 \mathrm{~mm}$; (B) Quantification of cholinergic neuron cell counts from three adjacent tissue sections per animal. A $\beta O$-injected rats had significantly more ChAT labelling in the basal forebrain compared to controls 21 days post-injection. Data presented as group means \pm SEM. * indicates statistical significance between A $\beta O$-injected and control rats using 2-way ANOVA followed by Tukey's post hoc analysis, $p<0.05, n=5$ for each experimental group.

\subsection{Microglia Activation in Response to A}

One of the earliest pathological consequences in the pathogenesis of AD includes an increased microglial response within several brain regions including the cortex, hippocampus, basal forebrain and white matter tracts [39]. To assess microglia activation an antibody specific to activated microglia (Ox-6) along with an antibody that labels all microglia (IBA-1) regardless of activation status was used (Figure 4). No significant differences were observed in either total microglia or activated microglia within the hippocampus or basal forebrain between A $\beta \mathrm{O}$-injected and controls (Figure 4). However, a significant increase in Ox-6 positive activated microglia was observed in $\mathrm{A} \beta \mathrm{O}$-injected rats at 21 days post-injection within the corpus callosum compared to control rats (Figure 4 , control $-6.5 \pm 1.8$ cells $/ \mathrm{mm}^{2}, \mathrm{~A} \beta \mathrm{O}-14.11 \pm 3.40$ cells $/ \mathrm{mm}^{2}$ ). 
A

IBA-1
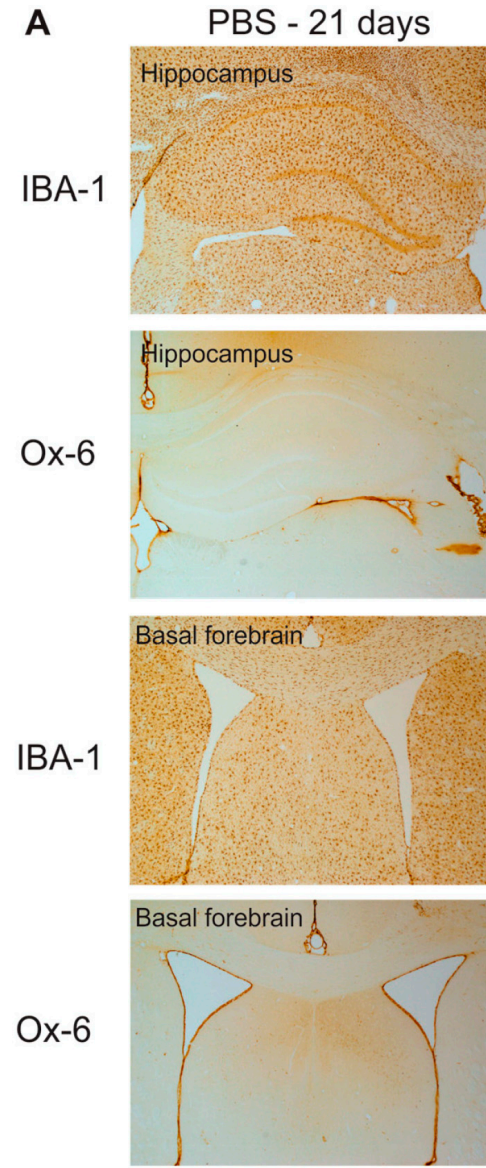

IBA-1
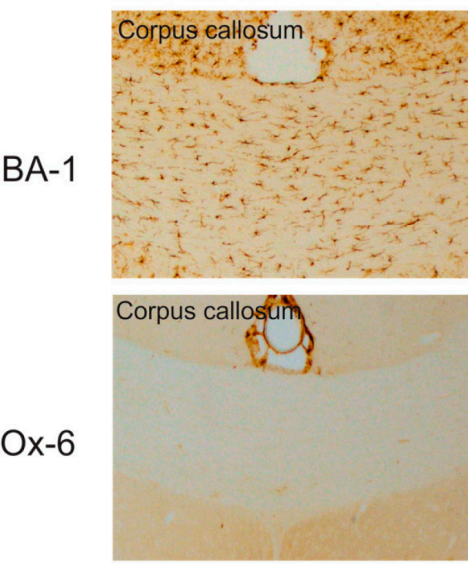

A $\beta 0$ - 21 days
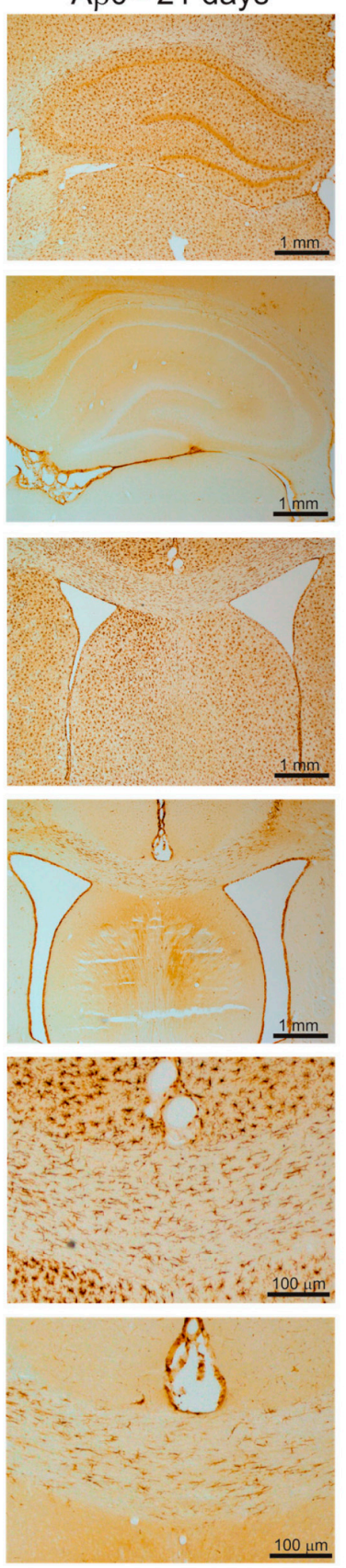
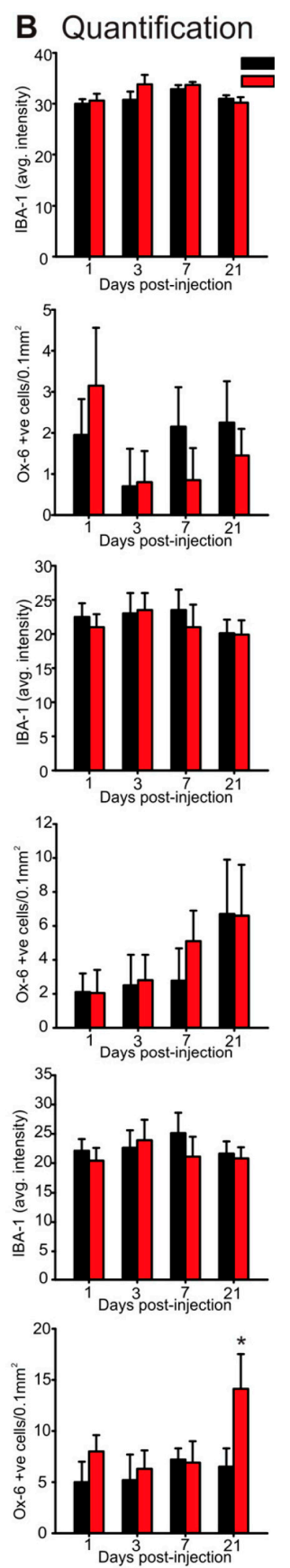

Figure 4. Microglia assessment in the hippocampus, basal forebrain and corpus callosum. Paraformaldehyde perfused rat brains were sectioned at $30 \mu \mathrm{m}$ and stained with either IBA- 1 antibody to label all microglia or Ox-6 antibody to label activated microglia in the hippocampus, basal forebrain and corpus callosum. (A) Photomicrographs of the hippocampus (top two panels) basal forebrain (middle two panels) and corpus callosum (bottom two panels) in in coronal rat brain sections from $\mathrm{A} \beta \mathrm{O}$-injected and PBS-injected (control) rats 21 days post-injection. Scale bars are $100 \mu \mathrm{m}$ or $1 \mathrm{~mm}$ as indicated; (B) quantification using optical densitometry (IBA-1) or activated microglia cell counts (Ox-6) from three adjacent tissue sections per animal. No differences in IBA-1 labelling were observed between $\mathrm{A} \beta \mathrm{O}$-injected and controls across all brain regions. A $\beta \mathrm{O}$-injected rats had significantly more Ox- 6 positive cells within the corpus callosum compared to controls 21 days post-injection. Data presented as group means $\pm \mathrm{SEM}$. * indicates statistical significance between $\mathrm{A} \beta \mathrm{O}$-injected and control rats using 2-way ANOVA followed by Tukey's post-hoc analysis, $p<0.05, n=5$ for each experimental group. 


\section{Discussion}

The early progression of $\mathrm{AD}$ still remains elusive. $\mathrm{A} \beta \mathrm{O}$ are potent neurotoxic proteins that may play a key role in this process. In vivo models of disease can help the field gain a better understanding on the effects of $A \beta O$ in disease pathogenesis. This study aimed to examine the effects of a single acute exposure of $\mathrm{A} \beta \mathrm{O}$ in the rat. To achieve this, rats were injected bilaterally with $\mathrm{A} \beta \mathrm{O}$ into the lateral ventricles and allowed to survive to multiple endpoints. Our results revealed a transient perturbation in learning and memory as well as mild anxiety-like behaviours. These behavioural deficits corresponded with a transient increase of $A \beta$ within the corpus callosum and cingulate gyrus, an increase in activated microglia within these same areas and a decrease in cholinergic neurons within the basal forebrain.

The Morris water maze task is commonly used to test in learning and memory impairment in rodent models of $\mathrm{AD}$ [40-42]. In the present study, we demonstrate that an acute exposure to $\mathrm{A} \beta \mathrm{O}$ induced transient behavioural learning and memory deficits. We showed that rats exposed to $\mathrm{A} \beta \mathrm{O}$ were slower to learn the task initially (day 9) and but performed to the same level as controls by day 11 . To test memory, probe trials were performed on days 12 and 19. A $\beta O$-injected rats only demonstrated impairment on day 12 and recovered on the test performance by day 19. Overall, these data suggest that the $\mathrm{A} \beta \mathrm{O}$ injections caused a mild and transient impairment in learning and memory. Previous studies using acute single injection of $A \beta$ peptides have shown similar acute deficits [43] indicating a potential role of these peptides in inducing transient impairments in memory and learning.

The open field task is used to analyze exploratory and anxiety-like behaviour [44]. Our results demonstrated that $\mathrm{A} \beta \mathrm{O}$-injected rats moved less and spent less time in the central zone. This significant difference may suggests anxiety-like behaviour [44]. More importantly, anxiety is an early clinical symptom commonly observed in patients diagnosed with AD. Similar anxiety-like behaviour was also observed in a transgenic rat carrying the Swedish human APP mutation (Tg6590). This rat also demonstrated increased levels of $\mathrm{A} \beta \mathrm{O}$ within the hippocampus and cortex [45]. An additional study using this rat line also demonstrated both anxiety-like behaviour with the open field task, as well as deficits in spatial learning and memory with the Morris water maze [46]. Combined with our data, this suggests that $\mathrm{A} \beta \mathrm{O}$ may play a role in inducing anxiety-like behaviour in the rat.

Pathological analysis on $\mathrm{A} \beta \mathrm{O}$-injected rats revealed a transient increase in $\mathrm{A} \beta$ labeling in the corpus callosum and cingulate gyrus that resolved by 21 days. This finding is congruent with the timing in the observed transient deficit in learning and memory. This indicates that the $\mathrm{A} \beta$ did indeed get into the brain parenchyma but was likely eventually cleared the brain parenchyma. It is possible, although unlikely given its anatomical location that the observed increase in $A \beta$ was endogenous rather than from the injected peptides. In another study, using a chronic injection approach in which the group injected $1 \mu \mathrm{g}$ of $\mathrm{A} \beta \mathrm{O} 3$ times per week for a total of 15 injections (total $15 \mu \mathrm{g}$ of $\mathrm{A} \beta \mathrm{O}$ compared to our $23 \mu \mathrm{g}$ single injection paradigm), they found positive $A \beta$ labelling within the hippocampus, entorhinal cortex, amygdala, and striatum [47]. These same regions were also identified in a study characterizing spatio-temporal progression of $\mathrm{A} \beta$ deposition in human $\mathrm{AD}$ brains [48] indicating that a chronic injection paradigm may recapitulate more aspects of the human disease than our single injection paradigm. Our rationale for injecting $23 \mu \mathrm{g}$ was to have the ability to inject the most amount of $\mathrm{A} \beta \mathrm{O}$ possible in a single bolus without using excessive injection volume. In our hands, a higher amount of $\mathrm{A} \beta \mathrm{O}$ results in precipitation of the peptide out of solution. We chose to use a single injection paradigm to reduce the potential for multiple inflammatory injuries seen with either chronic injections or multiple infusions. Moreover, by using a single injection paradigm, we could test if a single exposure of $\mathrm{A} \beta \mathrm{O}$ could seed further generation and deposition of $\mathrm{A} \beta \mathrm{O}$ in the rat brain. Our results in this study indicate that this was not the case. Our study, however, may potentially add a critical piece of information currently lacking in the field. In both human AD patients and AD animal models, increased deposition of $\mathrm{A} \beta \mathrm{O}$ within the brain parenchyma have correlated with decreased $\mathrm{A} \beta \mathrm{O}$ levels in cerebrospinal fluid (CSF) $[36,47,49-51]$. These studies suggest a connection between the levels of $\mathrm{A} \beta \mathrm{O}$ within the brain parenchyma and in the CSF. Further studies will need to carefully examine this 
relationship between brain parenchymal $\mathrm{A} \beta \mathrm{O}$ and CSF A $\beta O$ levels. Moreover, our study was the first to describe the resulting loss of cholinergic neurons within the basal forebrain. This is a key finding since a key pathological feature that defines $\mathrm{AD}$ cases in humans is cholinergic neuron loss within the basal forebrain [38]. Our in vivo findings need to be followed up with mechanistic studies aimed at understanding how $\mathrm{A} \beta \mathrm{O}$ exposure directly targets cholinergic neurons.

Although activated microglial cells seem to play a role in the pathogenesis of the disease, the effects on the outcome of the disease is uncertain. Different studies have concluded contradictory roles for activated microglia, specifically, whether it exacerbates or attenuates the neurotoxic effects of $A \beta O[52,53]$. Results from our study demonstrated an increase in activated microglia within the corpus callosum of $\mathrm{A} \beta \mathrm{O}$ injected rats. It was interesting that this difference was only observed 21 days following injury. It is possible that the deposition and clearance of $\mathrm{A} \beta \mathrm{O}$ left an additional injury resulting in this delayed microglia activation. Future studies need to be done to better understand the role of microglia activation in response to $\mathrm{A} \beta \mathrm{O}$ exposure in vivo. This will help shed light on the harmful vs. helpful role of microglia in AD.

In summary, our study found that exposure of $\mathrm{A} \beta \mathrm{O}$ into the rat brain resulted in transient deficits in spatial learning memory with a concomitant observation of anxiety-like behaviour. These behavioural deficits were concomitant a transient increase in $\mathrm{A} \beta$ deposition which was eventually cleared. The single exposure to $\mathrm{A} \beta \mathrm{O}$ also resulted in microglia activation in the corpus callosum indicating that $\mathrm{A} \beta \mathrm{O}$ can elicit inflammation in the white matter tracts. Future studies need to further elucidate the mechanism responsible, specifically for the loss of cholinergic neurons in response to $\mathrm{A} \beta \mathrm{O}$ exposure. By varying the dose and timing of exposure, it's possible to gain further insight into these mechanisms. Overall, results from this study and others suggest that exposure to $A \beta O$ in the rat may be a useful tool in assessing the early phases for the pathogenesis of AD.

\section{Materials and Methods}

\subsection{Synthetic $A \beta O$ Preparation}

$\mathrm{A} \beta \mathrm{O}$ were prepared as previously described [47]. Briefly, $\mathrm{A} \beta_{1-42}$ peptide (Bachem, Bubendorf, Switzerland) was purchased and stored at $-20^{\circ} \mathrm{C}$ until use. Ice-cold 1,1,1,3,3,3-hexafluro-2-propanol (HFIP, Sigma Aldrich, St. Louis, MO, USA) was added to dissolve the peptide and make a final of $1 \mathrm{mM}$. The solution was vortexed and aliquoted into microcentrifuge tubes with $10 \mu \mathrm{L}$ each. Tubes were air-dried on ice for $15 \mathrm{~min}$ and then lyophilized for $1 \mathrm{~h}$. Resulting peptide was stored at $-80^{\circ} \mathrm{C}$ until use. Prior to surgery, peptides were re-dissolved in $10 \mu \mathrm{L}$ of anhydrous dimethyl sulfoxide (DMSO, BioShop, Burlington, ON, Canada), sonicated for 10 mins at $37^{\circ} \mathrm{C}$, and $10 \mathrm{mM}$ phosphate buffered saline (PBS, pH 7.4) was added to make a final concentration of $150 \mu \mathrm{M}$. Immediately after adding PBS, peptide solution was incubated at $4{ }^{\circ} \mathrm{C}$ for $24 \mathrm{~h}$.

\subsection{Experimental Groups and Surgical Procedures}

All animal protocols were approved by Western University Animal Care Committee. Six-month old male Wistar rats (Charles River, Montreal, QC, Canada) were used for this study. Each rat was housed individually with food and water provided ad libitum. Rats were randomly assigned to either an experimental or a control group. Rats were also allowed to habituate to their new environment for at least one week prior to surgeries.

Rats were anaesthetized with 3\% isoflurane (Baxter Corporation, Mississauga, ON, Canada) and fixed onto a stereotaxic apparatus. Rats were kept under isoflurane throughout the surgery, body temperature was maintained at $37^{\circ} \mathrm{C}$ using a heating pad. Bilateral intracerebroventricular (ICV, AP: $-0.8 \mathrm{~mm}, \mathrm{ML}: \pm 1.4 \mathrm{~mm}, \mathrm{DV}:-4.0 \mathrm{~mm}$ ) injections were performed using a Hamilton syringe (Hamilton, Reno, NV, USA). A $\beta \mathrm{O}$ or $10 \mathrm{mM}$ phosphate buffered saline (PBS—control, pH 7.4) was injected into each ventricle ( $17 \mu \mathrm{L}$ per ventricle-23 $\mu \mathrm{g}$ peptide total) at a rate $\mu \mathrm{L} / \mathrm{min}$. Rats were given buprenorphine $(0.1 \mathrm{~mL} / 100 \mathrm{~g}$ body weight-Reckitt Benckiser Healthcare, Oakville, ON, Canada) 
subcutaneously and $0.03 \mathrm{~mL}$ Baytril (Bayer, Toronto, ON, Canada) intramuscularly. Following surgery, rats were monitored in a cage under a heat lamp until recovery from anaesthesia. A total of eight rat groups were used in this study. Rats were injected with either A $\beta \mathrm{O}$ or PBS and were euthanized at 1 $(n=5), 3(n=5), 7(n=5)$, or $21(n=8)$ days post-surgery. Rats euthanized at 21-days post-surgery underwent behavioural studies as described below. No differences in body weight changes were observed between the surgery and post-surgery day 21 (control— $+1.2 \pm 1.4 \mathrm{~g}, \mathrm{~A} \beta \mathrm{O}-+0.8 \pm 1.1 \mathrm{~g}$ ).

\subsection{Behavioural Assessments}

Morris water maze was performed to determine performance in spatial learning and memory. After surgery, rats were allowed to recover for one week before behavioural assessments began. Rats were subjected to four days of spatial learning between post-surgery days 8-11 and received four trials per day. During spatial learning, rats were given $90 \mathrm{~s}$ to find the submerged platform for each trial. If unsuccessful within the allotted time, rats would be guided to the platform. After each trial rats would remain on the platform for $30 \mathrm{~s}$. To begin each trial, the rat placement within the pool was randomly selected. Rats were subjected to one probe trial per day on post surgery day 12 and 19 to test for short and long-term spatial memory respectively. In these trials, rats were allowed to freely swim around the pool for $30 \mathrm{~s}$ while the platform was taken out. The rats were subjected to four trials per day to find the platform. The purpose of the cued learning trial was to control for the rats' ability to recognize a visual cue and their ability to swim towards the platform. All experiments were tracked using video-tracking software (ANY-maze, Wood Dale, IL, USA). Latency to reach target zone, latency to reach platform zone and mean swim speeds were measured.

Open field analysis (OF, Med Associates Inc., Fairfax, VA, USA) was used to assess exploratory and anxiety-like behaviours. Immediately after their last cued learning trial on post-surgery day 21, rats were moved to the room where $\mathrm{OF}$ was performed. Rats were allowed to rest and acclimate to the environment for at least $4 \mathrm{~h}$ prior to OF analysis. Boxes were cleaned with ethanol before and after each use. One rat was placed at the front and center of each box and allowed to explore for $20 \mathrm{~min}$. Ambulatory time, ambulatory distance, and vertical counts were measured.

\subsection{Pathological Analysis}

Rats were euthanized by injecting a lethal dose of Euthanyl (Bimeda-MTC, Cambridge, ON, Canada) intraperitoneally. Rats were perfused trans-aortically with $10 \mathrm{mM}$ PBS for $3 \mathrm{~min}$ followed by $4 \%$ paraformaldehyde for $7 \mathrm{~min}$. Brains were removed and placed in $4 \%$ PFA and stored at $4{ }^{\circ} \mathrm{C}$ for $24 \mathrm{~h}$. Brains were then transferred to $30 \%$ sucrose at $4{ }^{\circ} \mathrm{C}$ for $72 \mathrm{~h}$. Thirty $\mu \mathrm{m}$ coronal brain sections were sliced from the rat brain tissue using a CryoStar Nx50 (Thermo Scientific, Waltham, MA, USA). Sections were stored in cryoprotectant $(30 \%$ sucrose, phosphate buffer $\mathrm{pH}=7.2$, and ethylene glycol) at $-20^{\circ} \mathrm{C}$ until use. For immunohistochemistry labeling of $\mathrm{A} \beta$, Ox6 and ChAT, brain sections were washed in $10 \mathrm{mM}$ PBS to remove cryoprotectant. Endogenous peroxidase activity was then blocked by incubating sections with $1 \%$ hydrogen peroxide (Fisher Chemicals, Fair Lawn, NJ, USA). Sections were then washed $3 \times 5$ min with PBS and incubated at room temperature for $1 \mathrm{~h}$ in secondary antibody species raised specific serum (1:500) diluted in $10 \mathrm{mM}$ PBS. Sections were then washed in $10 \mathrm{mM}$ PBS $(3 \times 5 \mathrm{~min})$ followed by incubation overnight at $4{ }^{\circ} \mathrm{C}$ with either anti-mouse A $\beta 4 \mathrm{G} 8$ (1:500, Covance, Princeton, NJ, USA) which detects the 17-24 AA sequence of the A $\beta$ peptide, anti-mouse Ox-6 (1:1000, Pharmingen, San Jose, CA, USA) which detects the major histocompatibility complex (MHC) class II of activated microglia, anti-rabbit IBA-1 (1:1000, Wako, Richmond, VA, USA) which detects the ionized calcium binding adapter molecule of all microglia or anti-mouse choline acetyltransferase (ChAT, 1:500, Abcam, Cambridge, MA, USA) which detects cholinergic neurons via the anti-choline acetyltransferase enzyme. Sections were incubated at their respective concentrations diluted in $10 \mathrm{mM}$ PBS with $0.2 \%$ Triton X-100. Sections were then washed in $10 \mathrm{mM}$ PBS $(3 \times 5 \mathrm{~min})$ followed by incubation in horse radish peroxidase tagged donkey anti-mouse or donkey anti-rabbit secondary antibodies diluted in serum and $10 \mathrm{mM}$ PBS for $1 \mathrm{~h}$ at room temperature. Sections were then washed in $10 \mathrm{mM}$ PBS 
$(3 \times 5 \mathrm{~min})$ followed by incubation in $2 \%$ avidin-biotin complex (Vectastain Elite ABC Kit, Vector Laboratories, Inc., Burlingame, CA, USA) for one hour at room temperature. Finally, sections were incubated in 0.05\% 3,3'-diaminobenzidine tetrahydrochloride (DAB; Sigma, Toronto, ON, Canada) and $1 \% \mathrm{H}_{2} \mathrm{O}_{2}$ for $15 \mathrm{~min}$ at room temperature. Sections were dehydrated in increasing concentrations of alcohol, cleared in xylene, and mounted with Depex mounting medium (Depex, BDH Chemicals, Poole, UK). To ensure consistency, sections from different surgical groups were processed at the same time.

\subsection{Imaging Investigators Were Blinded to Surgical Identity for All Image Acquisition}

Imaging was performed using a Nikon Eclipse Ni-U upright microscope with a DS-Fi2 high definition color camera and imaging software NIS Elements Colour Camera (Nikon Instruments, Melville, NY, USA). For all optimal densitometry analysis, images were taken at the same exposure time. Optical densitometry was performed on a minimum of three 8-bit scale grey images per region per animal (ImageJ64 software, National Institute of Health, Bethesda, MD, USA).

\subsection{Statistical Analysis}

Investigators were blinded to surgical group identities for all analysis. Statistical analysis was completed using GraphPad Prism 6.0 (La Jolla, CA, USA). Either a student's $t$ tests, one-way or two-way analysis of variance (ANOVA) followed by Tukey's multiple comparisons post-hoc tests were performed where appropriate. Data are expressed as means \pm standard error of the mean (SEM). An asterisk $\left({ }^{*}\right)$ indicates statistical significance between group means with $p<0.05$.

Acknowledgments: We thank Lynn Wang and Rahul Mor for their technical assistance and expertise. We also thank the efforts of the Animal Care staff at Western University for their care of the animals. This work is funded by grants from the Canadian Institutes for Health Research (CIHR), Natural Sciences and Engineering Research Council (NSERC), Canadian Consortium for Neurodegeneration and Aging (CCNA) and Canadian Foundation for Innovation (CFI) to SNW.

Author Contributions: Ryan S. Wong performed all experiments and data analysis and wrote the manuscript. David F. Cechetto helped with study conception, reviewed and edited the manuscript. Shawn N. Whitehead conceived the study, performed data analysis and wrote, reviewed and edited the manuscript.

Conflicts of Interest: The authors declare no conflict of interest.

\section{References}

1. Haass, C.; Kaether, C.; Thinakaran, G.; Sisodia, S. Trafficking and proteolytic processing of APP. Cold Spring Harb. Perspect. Med. 2012, 2. [CrossRef] [PubMed]

2. Shoji, M.; Golde, T.; Ghiso, J.; Cheung, T.; Estus, S.; Shaffer, L.; Cai, X.-D.; McKay, D.; Tintner, R.; Frangione, B.; et al. Production of the Alzheimer amyloid $\beta$ protein by normal proteolytic processing. Science 1992, 258, 126-129. [CrossRef] [PubMed]

3. Seubert, P.; Vigo-Pelfrey, C.; Esch, F.; Lee, M.; Dovey, H.; Davis, D.; Sinha, S.; Schlossmacher, M.; Whaley, J.; Swindlehurst, $\mathrm{C}$. Isolation and quantification of soluble Alzheimer's $\beta$-peptide from biological fluids. Nature 1992, 359, 325-327. [CrossRef] [PubMed]

4. Haass, C.; Schlossmacher, M.; Hung, A.; Vigo-Pelfrey, C.; Mellon, A.; Ostaszewski, B.L.; Lieberburg, I.; Koo, E.; Schenk, D.; Teplow, D.; et al. Amyloid $\beta$ peptide is produced by cultured cells during normal metabolism. Nature 1992, 359, 322-325. [CrossRef] [PubMed]

5. Wong, C.W.; Quaranta, V.; Glenner, G.G. Neuritic plaques and cerebrovascular amyloid in Alzheimer disease are antigenically related. Proc. Natl. Acad. Sci. USA 1985, 82, 8729-8732. [CrossRef] [PubMed]

6. Haass, C.; Selkoe, D.J. Soluble protein oligomers in neurodegeneration: lessons from the Alzheimer's amyloid $\beta$-peptide. Nat. Rev. Mol. Cell Biol. 2007, 8, 101-112. [CrossRef] [PubMed]

7. Kang, J.; Lemaire, H.-G.; Unterbeck, A.; Salbaum, J.M.; Masters, C.L.; Grzeschik, K.-H.; Multhaup, G.; Beyreuther, K.; Muller-Hill, B. The precursor of Alzheimer's disease amyloid A4 protein resembles a cell-surface receptor. Nature 1987, 325, 733-736. [CrossRef] [PubMed]

8. Haass, C.; Selkoe, D.J. Cellular processing of $\beta$-amyloid precursor protein and the genesis of amyloid $\beta$-peptide. Cell 1993, 75, 1039-1042. [CrossRef] 
9. Gellermann, G.P.; Byrnes, H.; Striebinger, A.; Ullrich, K.; Mueller, R.; Hillen, H.; Barghorn, S. A $\beta$-globulomers are formed independently of the fibril pathway. Neurobiol. Dis. 2008, 30, 212-220. [CrossRef] [PubMed]

10. Ahmed, M.; Davis, J.; Aucoin, D.; Sato, T.; Ahuja, S.; Aimoto, S.; Elliott, J.I.; van Nostrand, W.E.; Smith, S.O. Structural conversion of neurotoxic amyloid- $\beta_{1-42}$ oligomers to fibrils. Nat. Struct. Mol. Biol. 2010, 17, 561-567. [CrossRef] [PubMed]

11. Rangachari, V.; Moore, B.D.; Reed, D.K.; Sonoda, L.K.; Bridges, A.W.; Conboy, E.; Hartigan, D.; Rosenberry, T.L. Amyloid-B $\mathrm{B}_{1-42}$ rapidly forms protofibrils and oligomers by distinct pathways in low concentrations of sodium dodecylsulfate. Biochemistry 2007, 46, 12451-12462. [CrossRef] [PubMed]

12. Hardy, J.A.; Higgins, G.A. Alzheimer's disease: Amyloid cascade hypothesis. Science 1992, 256, $184-185$. [CrossRef] [PubMed]

13. Glenner, G.G.; Wong, C.W. Alzheimer's disease: Initial report of the purification and characterization of a novel cerebrovascular amyloid protein. Biochem. Biophys. Res. Commun. 1984, 120, 885-890. [CrossRef]

14. Hardy, J.; Selkoe, D.J. The amyloid hypothesis of Alzheimer's Disease: Progress and problems on the road to therapeutics. Sci. Compass Rev. 2002, 297, 353-356. [CrossRef] [PubMed]

15. Stelzmann, R.A.; Schnitzlein, H.N.; Murtagh, F.R. An English translation of Alzheimer's 1907 paper, "uber eine eigenartige erkankung der hirnrinde". Clin. Anat. 1995, 8, 429-431. [CrossRef] [PubMed]

16. Gong, Y.; Chang, L.; Viola, K.L.; Lacor, P.N.; Lambert, M.P.; Finch, C.E.; Krafft, G.A.; Klein, W.L. Alzheimer's disease-affected brain: Presence of oligomeric A $\beta$ ligands (ADDLs) suggests a molecular basis for reversible memory loss. Proc. Natl. Acad. Sci. USA 2003, 100, 10417-10422. [CrossRef] [PubMed]

17. Verdile, G.; Fuller, S.; Atwood, C.S.; Laws, S.M.; Gandy, S.E.; Martins, R.N. The role of $\beta$ amyloid in Alzheimer's disease: Still a cause of everything or the only one who got caught? Pharmacol. Res. 2004, 50, 397-409. [CrossRef] [PubMed]

18. McLean, C.A.; Cherny, R.A.; Fraser, F.W.; Fuller, S.J.; Smith, M.J.; Beyreuther, K.; Bush, A.I.; Masters, C.L. Soluble pool of $A \beta$ amyloid as a determinant of severity of neurodegeneration in Alzheimer's disease. Ann. Neurol. 1999, 46, 860-866. [CrossRef]

19. Hibbard, L.S.; McKeel, D.W., Jr. Automated identification and quantitative morphometry of the senile plaques of Alzheimer's disease. Anal. Quant. Cytol. Histol. Int. Acad. Cytol. 1997, 19, 123-138.

20. Crystal, H.; Dickson, D.W.; Fuld, P.; Masur, D.; Scott, R.W.; Mehler, M.; Wolfson, L. Clinico-pathologic studies in dementia Nondemented subjects with pathologically confirmed Alzheimer's disease. Neurology 1988, 38, 1682. [CrossRef] [PubMed]

21. Westerman, M.A.; Cooper-Blacketer, D.; Mariash, A.; Kotilinek, L.; Kawarabayashi, T.; Younkin, L.H.; Carlson, G.A.; Younkin, S.G.; Ashe, K.H. The relationship between A $\beta$ and memory in the Tg2576 mouse model of Alzheimer's disease. J. Neurosci. 2002, 22, 1858-1867. [PubMed]

22. Oda, T.; Wals, P.; Osterburg, H.H.; Johnson, S.A.; Pasinetti, G.M.; Morgan, T.E.; Rozovsky, I.; Stine, W.B.; Snyder, S.W.; Holzman, T.F. Clusterin (apoJ) alters the aggregation of amyloid $\beta$-peptide $\left(\mathrm{A} \beta_{1-42}\right)$ and forms slowly sedimenting A $\beta$ complexes that cause oxidative stress. Exp. Neurol. 1995, 136, 22-31. [CrossRef] [PubMed]

23. Lue, L.F.; Kuo, Y.M.; Roher, A.E.; Brachova, L.; Shen, Y.; Sue, L.; Beach, T.; Kurth, J.H.; Rydel, R.E.; Rogers, J. Soluble amyloid $\beta$ peptide concentration as a predictor of synaptic change in Alzheimer's disease. Am. J. Pathol. 1999, 155, 853-862. [CrossRef]

24. Shankar, G.M.; Li, S.; Mehta, T.H.; Garcia-Munoz, A.; Shepardson, N.E.; Smith, I.; Brett, F.M.; Farrell, M.A.; Rowan, M.J.; et al. Amyloid- $\beta$ protein dimers isolated directly from Alzheimer's brains impair synaptic plasticity and memory. Nat. Med. 2008, 14, 837-842. [CrossRef] [PubMed]

25. Lambert, M.P.; Barlow, A.K.; Chromy, B.A.; Edwards, C.; Freed, R.; Liosatos, M.; Morgan, T.E.; Rozovsky, I.; Trommer, B.; Viola, K.L.; et al. Diffusible, nonfibrillar ligands derived from A $\beta 1-42$ are potent central nervous system neurotoxins. Proc. Natl. Acad. Sci. USA 1998, 95, 6448-6453. [CrossRef] [PubMed]

26. Lacor, P.N.; Buniel, M.C.; Chang, L.; Fernandez, S.J.; Gong, Y.; Viola, K.L.; Lambert, M.P.; Velasco, P.T.; Bigio, E.H.; Finch, C.E.; et al. Synaptic targeting by Alzheimer's-related amyloid $\beta$ oligomers. J. Neurosci. 2004, 24, 10191-10200. [CrossRef] [PubMed]

27. Wang, Q. Block of long-term potentiation by naturally secreted and synthetic amyloid-peptide in hippocampal slices is mediated via activation of the kinases c-Jun N-Terminal kinase, cyclin-dependent kinase 5, and p38 mitogen-activated protein kinase as well as M. J. Neurosci. 2004, 24, 3370-3378. [CrossRef] [PubMed] 
28. Walsh, D.M.; Townsend, M.; Podlisny, M.B.; Shankar, G.M.; Fadeeva, J.V.; El Agnaf, O.; Hartley, D.M.; Selkoe, D.J. Certain inhibitors of synthetic amyloid $\beta$-peptide $(\mathrm{A} \beta)$ fibrillogenesis block oligomerization of natural $A \beta$ and thereby rescue long-term potentiation. J. Neurosci. 2005, 25, 2455-2462. [CrossRef] [PubMed]

29. Salminen, A.; Ojala, J.; Kauppinen, A.; Kaarniranta, K.; Suuronen, T. Inflammation in Alzheimer's disease: Amyloid-B oligomers trigger innate immunity defence via pattern recognition receptors. Prog. Neurobiol. 2009, 87, 181-194. [CrossRef] [PubMed]

30. Heppner, F.L.; Ransohoff, R.M.; Becher, B. Immune attack: The role of inflammation in Alzheimer disease. Nat. Rev. Neurosci. 2015, 16, 358-372. [CrossRef] [PubMed]

31. Walter, S.; Letiembre, M.; Liu, Y.; Heine, H.; Hao, W.; Bode, B.; Manietta, N.; Schulz-schäffer, W.; Faßbender, K. Cellular physiology and biochemistr y biochemistry role of the Toll-Like receptor 4 in Neuro- inflammation in Alzheimer's disease. Cell. Physiol. Biochem. 2007, 20, 947-956. [CrossRef] [PubMed]

32. Lesné, S.; Koh, M.T.; Kotilinek, L.; Kayed, R.; Glabe, C.G.; Yang, A.; Gallagher, M.; Ashe, K.H. A specific amyloid- $\beta$ protein assembly in the brain impairs memory. Nature 2006, 440, 352-357. [CrossRef] [PubMed]

33. Catalano, S.M.; Dodson, E.C.; Henze, D.A.; Joyce, J.G.; Krafft, G.A.; Kinney, G.G. The role of amyloid- $\beta$ derived diffusible ligands (ADDLs) in Alzheimer's disease. Curr. Top. Med. Chem. 2006, 6, 597-608. [CrossRef] [PubMed]

34. Walsh, D.M.; Klyubin, I.; Fadeeva, J.V.; Cullen, W.K.; Anwyl, R.; Wolfe, M.S.; Rowan, M.J.; Selkoe, D.J. Naturally secreted oligomers of amyloid $\beta$ protein potently inhibit hippocampal long-term potentiation in vivo. Nature 2002, 416, 535-539. [CrossRef] [PubMed]

35. Klyubin, I.; Walsh, D.M.; Lemere, C.A.; Cullen, W.K.; Shankar, G.M.; Betts, V.; Spooner, E.T.; Jiang, L.; Anwyl, R.; Selkoe, D.J.; et al. Amyloid $\beta$ protein immunotherapy neutralizes A $\beta$ oligomers that disrupt synaptic plasticity in vivo. Nat. Med. 2005, 11, 556-561. [CrossRef] [PubMed]

36. Kayed, R.; Head, E.; Thompson, J.L.; McIntire, T.M.; Milton, S.C.; Cotman, C.W.; Glabe, C.G. Common structure of soluble amyloid oligomers implies common mechanism of pathogenesis. Science 2003, 300, 486-489. [CrossRef] [PubMed]

37. Reed, M.N.; Hofmeister, J.J.; Jungbauer, L.; Welzel, A.T.; Yu, C.; Sherman, M.A.; Lesné, S.; LaDu, M.J.; Walsh, D.M.; Ashe, K.H.; et al. Cognitive effects of cell-derived and synthetically derived A $\beta$ oligomers. Neurobiol. Aging 2011, 32, 1784-1794. [CrossRef] [PubMed]

38. Francis, P.T.; Palmer, A.M.; Snape, M.; Wilcock, G.K. The cholinergic hypothesis of Alzheimer's disease: A review of progress. J. Neurol. Neurosurg. Psychiatry 1999, 66, 137-147. [CrossRef] [PubMed]

39. Heneka, M.T.; Golenbock, D.T.; Latz, E.; Anbarasi, M.S. Innate immunity in Alzheimer's disease. Nat. Immunol. 2015, 16, 229-236. [CrossRef] [PubMed]

40. Echeverria, V.; Ducatenzeiler, A.; Dowd, E.; Jänne, J.; Grant, S.M.; Szyf, M.; Wandosell, F.; Avila, J.; Grimm, H.; Dunnett, S.B.; et al. Altered mitogen-activated protein kinase signaling, tau hyperphosphorylation and mild spatial learning dysfunction in transgenic rats expressing the $\beta$-amyloid peptide intracellularly in hippocampal and cortical neurons. Neuroscience 2004, 129, 583-592. [CrossRef] [PubMed]

41. Leon, W.C.; Canneva, F.; Partridge, V.; Allard, S.; Ferretti, M.T.; DeWilde, A.; Vercauteren, F.; Atifeh, R.; Ducatenzeiler, A.; Klein, W.; et al. A novel transgenic rat model with a full Alzheimer's-like amyloid pathology displays pre-plaque intracellular amyloid- $\beta$-associated cognitive impairment. J. Alzheimer Dis. 2010, 20, 113-126.

42. D'Hooge, R.; de Deyn, P.P. Applications of the MORRIS water maze in the study of learning and memory. Brain Res. Rev. 2001, 36, 60-90. [CrossRef]

43. Nell, H.J.; Whitehead, S.N.; Cechetto, D.F. Age-dependent effect of $\beta$-amyloid toxicity on basal forebrain cholinergic neurons and inflammation in the rat brain. Brain Pathol. 2015, 25, 531-542. [CrossRef] [PubMed]

44. Prut, L.; Belzung, C. The open field as a paradigm to measure the effects of drugs on anxiety-like behaviors: A review. Eur. J. Pharmacol. 2003, 463, 3-33. [CrossRef]

45. Folkesson, R.; Malkiewicz, K.; Kloskowska, E.; Nilsson, T.; Popova, E.; Bogdanovic, N.; Ganten, U.; Ganten, D.; Bader, M.; Winblad, B.; et al. A transgenic rat expressing human APP with the Swedish Alzheimer's disease mutation. Biochem. Biophys. Res. Commun. 2007, 358, 777-782. [CrossRef] [PubMed]

46. Kloskowska, E.; Pham, T.M.; Nilsson, T.; Zhu, S.; Öberg, J.; Codita, A.; Pedersen, L.; Pedersen, J.T.; Malkiewicz, K.; Winblad, B.; et al. Cognitive impairment in the Tg6590 transgenic rat model of Alzheimer's disease. J. Cell. Mol. Med. 2010, 14, 1816-1823. [CrossRef] [PubMed] 
47. Forny-Germano, L.; Lyra e Silva, N.M.; Batista, A.F.; Brito-Moreira, J.; Gralle, M.; Boehnke, S.E.; Coe, B.C.; Lablans, A.; Marques, S.A.; Martinez, A.M.B.; et al. Alzheimer's disease-like pathology induced by amyloid-oligomers in nonhuman primates. J. Neurosci. 2014, 34, 13629-13643. [CrossRef] [PubMed]

48. Thal, D.R.; Rüb, U.; Orantes, M.; Braak, H. Phases of A $\beta$-deposition in the human brain and its relevance for the development of AD. Neurology 2002, 58, 1791-1800. [CrossRef] [PubMed]

49. Kawarabayashi, T.; Younkin, L.H.; Saido, T.C.; Shoji, M.; Ashe, K.H.; Younkin, S.G. Age-dependent changes in brain, CSF, and plasma amyloid $\beta$ protein in the Tg2576 transgenic mouse model of Alzheimer's disease. J. Neurosci. 2001, 21, 372-381. [PubMed]

50. Larson, M.E.; Lesné, S.E. Soluble A $\beta$ oligomer production and toxicity. J. Neurochem. 2012, 120, $125-139$. [CrossRef] [PubMed]

51. Lesné, S.E. Breaking the code of amyloid- $\beta$ oligomers. Int. J. Cell Biol. 2013, 2013, 950783. [CrossRef] [PubMed]

52. Sondag, C.M.; Dhawan, G.; Combs, C.K. Beta amyloid oligomers and fibrils stimulate differential activation of primary microglia. J. Neuroinflamm. 2009, 6, 1. [CrossRef] [PubMed]

53. Doi, Y.; Mizuno, T.; Maki, Y.; Jin, S.; Mizoguchi, H.; Ikeyama, M.; Doi, M.; Michikawa, M.; Takeuchi, H.; Suzumura, A. Microglia activated with the toll-like receptor 9 ligand CpG attenuate oligomeric amyloid $\beta$ neurotoxicity in in vitro and in vivo models of Alzheimer's disease. Am. J. Pathol. 2009, 175, 2121-2132. [CrossRef] [PubMed]

(C) 2016 by the authors; licensee MDPI, Basel, Switzerland. This article is an open access article distributed under the terms and conditions of the Creative Commons Attribution (CC-BY) license (http://creativecommons.org/licenses/by/4.0/). 